\title{
EXPORTACIONES DE CAPITAL HACIA LOS PAISES NUEVOS: LOS BANCOS FRANCESES Y LAS FINANZAS PUBLICAS ARGENTINAS, 1881-1887
}

\author{
ANDRES MARTIN REGALSKY \\ Buenos Aires
}

Uno de los fenómenos más característicos de la economía mundial en la segunda mitad del siglo xIx fue, sin duda, la masiva exportación de capitales desde los países más avanzados de Europa hacia los denominados «países nuevos». Este flujo de capitales estuvo estrechamente relacionado con la fuerte expansión del comercio internacional, y especialmente con la creciente demanda de bienes primarios de las mismas naciones receptoras ${ }^{1}$.

Como parte de este proceso, la Argentina fue uno de los países que recibió un mayor volumen de capital, particularmente en el curso de la década de 1880. Desde hacía muchos años que venía llamando la atención de los inversores: sus enormes extensiones de tierras fértiles de clima templado aún sin explotar parecían augurar un desarrollo agrario similar al de los Estados Unidos y un provechoso rendimiento para los capitales invertidos en actividades conexas. Estas condiciones se potenciaron al comenzar la década de 1880 en virtud de una serie de factores: la conclusión de la guerra de fronteras con los indígenas, que duplicaba la superficie susceptible de explotación; la continua baja de los fletes marítimos, que aumentaba la variedad de productos que podian colocarse en los lejanos mercados europeos, y la federalización de Buenos Aires, que abría un período de estabilidad y fortalecía al Estado nacional, principal garante de las inversiones extranjeras. Por eso no puede extrañar que el volumen de estas inversiones aumentara, de unos 100 millones de pesos/oro al final del ciclo $1862-75$, a unos 900 millones hacia $1890^{2}$.

Al igual que en otros países nuevos, los inversores británicos tuvieron una presencia dominante en los principales sectores, e incluso fueron por largo tiempo los únicos operadores extranjeros ${ }^{3}$. Probablemente por esta causa, no

' Sobre este tema pueden consultarse Feis (1930), Hall (1968), Adler (1967) y, como obras de divulgación, Woodruff (1977) y Ashworth (1978).

2 A efectos comparativos deben tenerse en cuenta las siguientes equivalencias: 1 peso $(\$) / o r o=5$ francos, y 5,04 pesos/oro $=1$ libra. El estudio general inás importante sobre las inversiones extranjeras del período es el ded Williams (1920). Sobre el papel de estas inversiones en el crecimiento argentino puede consultarse Gallo y Cortés Conde (1967).

${ }^{3}$ Véase al respecto el clásico trabajo de Ferns (1966), especialmente los caps. XI-XIII. 
suele valorarse debidamente la importancia alcanzada por los grupos inversores de otros orígenes, que a partir de 1880 comenzaron a desplegar una intensa actividad en diversos campos, especialmente en el de los empréstitos públicos ${ }^{4}$.

Este rubro había constituido, desde los primeros tiempos de la independencia, una esfera de acción privativa de los bancos de Londres ${ }^{5}$. Sin embargo, a principios de la década de 1880 , precisamente cuando se verificaron los mayores empréstitos del período, los banqueros británicos resultaron desplazados por un nuevo tipo de competidores: los grandes establecimientos de crédito de París. Alentados por la expansión que se venía registrando en esa plaza financiera, los banqueros franceses intentaron desarrollar un mercado alternativo al de Londres para los valores argentinos. Entre 1881 y 1885 lograron contratar la totalidad de los empréstitos externos del Gobierno argentino, que, vinculados a un vasto programa de obras públicas y saneamiento monetario, sumaron unos 67 millones de pesos/oro, sobre un total de inversiones extranjeras de 177 millones ${ }^{6}$.

Este caso, que ha sido considerado de manera general en algunos artículos recientes, presenta diversos puntos de interés insuficientemente esclarecidos, que serán objeto de análisis en el presente trabajo? Por una parte, procuraremos establecer los factores que posibilitaron el predominio de los grupos franceses en este campo de inversiones, la incidencia de sus peculiares modalidades operativas y el grado en que lograron cumplir su objetivo de constituir en París un centro financiero alternativo. Por otra parte, evaluaremos algunas repercusiones de estos negocios: la rentabilidad que reportaron a los grupos inversores; su influencia sobre la situación financiera local, particularmente en la crisis de $1884-85$, y su eventual utilización como herramienta para favorecer las exportaciones francesas de mercancías.

4 La presencia de estas nuevas inversiones, como resultado de la creciente internacionalización de las relaciones financieras, ha sido considerada por Marichal (1984), p. 48.

${ }^{3}$ Para las inversiones extranjeras en empréstitos públicos, véase Peters (1934). Para los empréstitos anteriores a 1880, Platt (1983) y Amaral (1984).

- En ambos casos hemos tomado los montos nominales. Para los empréstitos franceses nos hemos basado en Agote (1881), p. 62; (1883), pp. 13-14; (1884), pp. 9.10 y 145-147; (1885), pp. $8-10$, y (1887), p. 30 . Para las inversiones extranjeras de $1881-85$ nos basamos en Williams $(1920)$, p. 43 , cuyas cifras hemos corregido.

T Se trata de dos excelentes trabajos de Jones (1972) y Marichal (1984). Como se verá más adelante, diferimos con Jones en la valoración de los resultados que, desde la perspectiva del Gobierno argentino, arrojó esta diversificación de las fuentes de financiación externas, y con Marichal, en cuanto a sus apreciaciones sobre la relación de estas operaciones con las exportaciones francesas de mercancías. 


\section{El mercado de París y la conformación de los grupos inversores franceses}

La introducción de los grupos franceses en la Argentina puede explicarse en gran medida atendiendo a los importantes cambios ocurridos entonces en el mercado de París. Dichos cambios tuvieron su origen en las grandes operaciones financieras de 1870.73, destinadas al pago de indemnizaciones a Prusia. Por su elevado monto e interés, estas operaciones posibilitaron una ampliación del mercado, atrayendo a la masa de los pequeños ahorristas. Simultáneamente, condujeron a un fortalecimiento de los grandes establecimientos bancarios, que fueron los que estuvieron a cargo de las mismas. Bajo la presión de sus crecientes recursos y en respuesta a la demanda de un público ávido de nuevas colocaciones, estos bancos emprendieron la búsqueda de negocios de gran escala en un radio geográfico más amplio ${ }^{8}$.

Hasta entonces las inversiones francesas se habían canalizado principalmente hacia el continente europeo (en especial a España e Italia) y hacia negocios más o menos especulativos en el Oriente Medio y en algunos países latinoamericanos (México, Perú y Honduras) ${ }^{9}$. La reorientación se impuso durante el auge financiero de 1879-81, que se caracterizó por un alza general de las cotizaciones y resultó, por ende, propicio para la colocación de nuevas clases de títulos. Fue entonces cuando los banqueros franceses comenzaron a interesarse en los «países nuevos», de acuerdo con una tendencia que ya se había impuesto en el caso de las exportaciones británicas de capital. En tal sentido, los empréstitos argentinos constituyeron las primeras operaciones francesas de este tipo en el área sudamericana, que luego se extenderían a Brasil y Venezuela, y que engrosarían un novedoso rubro de los listados bursátiles: el de los «valores exóticos».

Un rasgo saliente en el accionar de los bancos franceses, que les permitió competir exitosamente por los empréstitos argentinos, fue su asociación en sindicatos y consorcios. El principal estuvo constituido por Paribas (Banque de Paris et des Pays Bas), Comptoir (Comptoir d'Escompte) y Caben (L. et R. Cahen d'Anvers), que participaron conjuntamente en los empréstitos de Ferrocarriles, Billetes de Tesorería, Banco Nacional, Obras de Salubridad y Obras Públicas II. El otro estuvo conformado por Générale e Industriel (Société Générale y Crédit Industriel e Commercial, respectivamente), que intervinieron en los empréstitos de Obras Públicas I y I (véase cuadro 1).

Esta modalidad de agrupamiento contrastaba notablemente con las prácticas adoptadas por la banca británica, que había actuado individualmente en los empréstitos argentinos anteriores. Dado el sistema de contratación en fir-

\footnotetext{
- Bouvier (1968), pp. 93-134; Vidal (1910); Feis (1930), pp. 33-43.

- Cameron (1971), p. 96.
} 


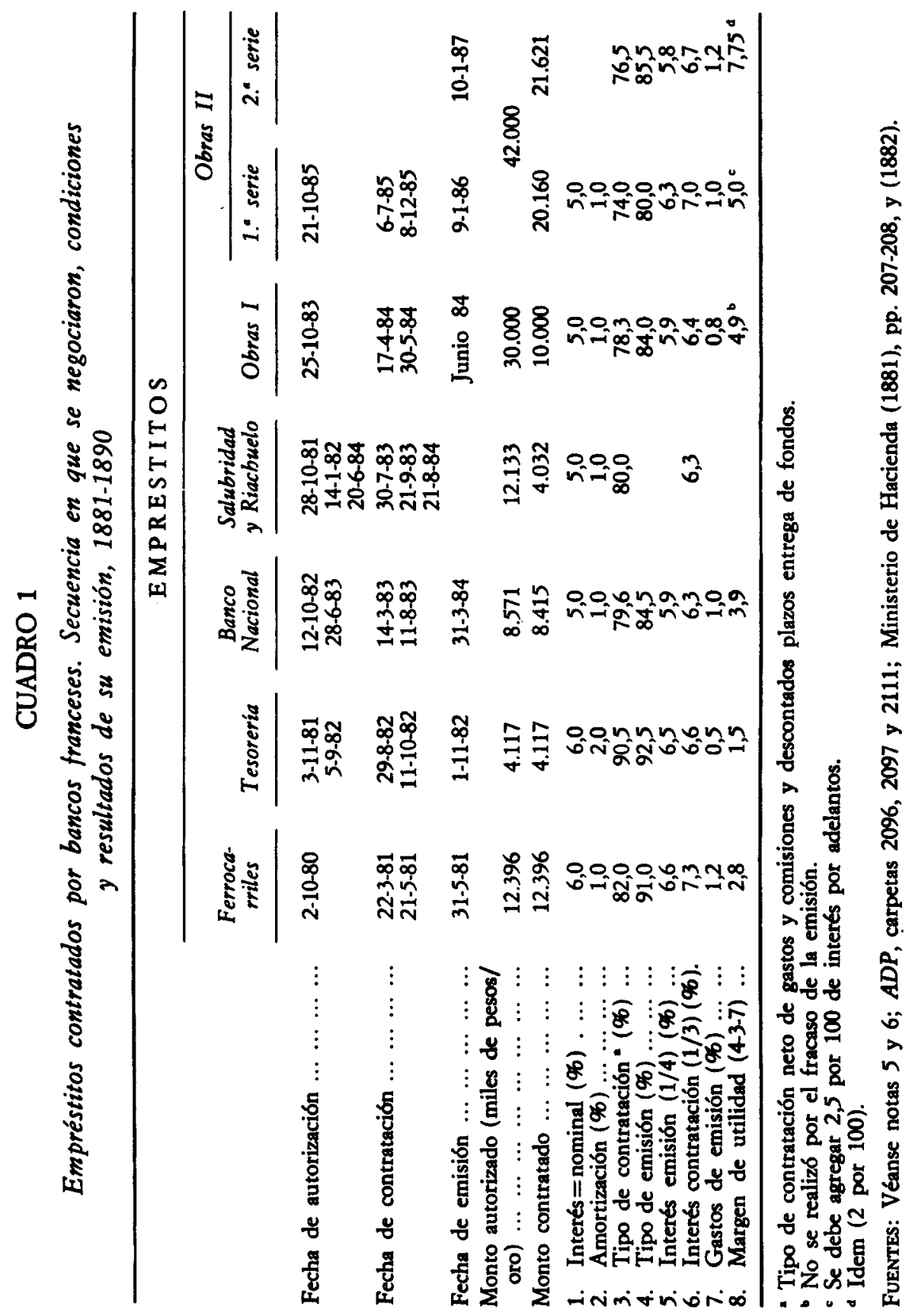


me que se aplicó en los nuevos empréstitos, por el cual los banqueros debían comprar anticipadamente los títulos para emitirlos luego bajo su propia responsabilidad, la modalidad francesa resultó más conveniente, al permitir una mayor distribución de estos riesgos. También resultó necesaria para facilitar la colocación de los títulos, pues en el mercado de París esa tarea la realizaban los propios bancos, a diferencia de lo que sucedía en Londres, donde corría a cargo de los agentes bursátiles ${ }^{10}$.

Dentro de cada grupo hubo una cierta división de tareas, que reflejaba en distinto grado la situación imperante en el sistema financiero francés. Los bancos de depósitos, así llamados por trabajar principalmente con recursos de corto plazo de su vasta clientela, comenzaban a especializarse en las operaciones de menor riesgo y duración. Los negocios más riesgosos y que implicaban una inmovilización de fondos más prolongada iban quedando a cargo de los denominados banques d'affaires, "bancos de negocios», que operaban en base a un importante capital propio y a los aportes de grandes clientes "

Estas líneas de especialización se verificaron particularmente en la conformación del primer grupo. El banco de negocios Paribas fue el que asumió la conducción y el que tomó una mayor participación en la contratación (el 57,1 por 100 en el empréstito de Obras Públicas II) ${ }^{12}$. Las tareas de emisión quedaron principalmente a cargo de Comptoir, uno de los mayores bancos de depósitos, que disponía de una amplia red de sucursales a través de las cuales podía canalizar los títulos hacia el público. El banco privado Caben, que tomó una pequeña participación en la contratación y no intervino en la émisión, no dejó por ello de desempeñar un papel crucial. Fue el que proveyó los contactos locales indispensables para captar los negocios, a través de sus influyentes agentes en Buenos Aires, Bemberg, Heimendabl y Compañia.

En el otro grupo, en cambio, las diversas funciones fueron desempeñadas por un mismo establecimiento. Su conducción estuvo a cargo de Générale, otro importante banco de depósitos que no se había plegado todavía a la línea adoptada por la mayoría de las entidades de este tipo y que seguía participando en operaciones de alto riesgo en competencia con la banca de inversión. Este banco tomó una participación mayoritaria, tanto en la emisión como en la contratación (el 62,5 por 100 de la parte firme del empréstito de Obras I) ${ }^{13}$. Industriel, que era de hecho una filial del anterior establecimiento, respondió por los saldos restantes. Los contactos locales fueron provistos, igualmente, por Générale, que desde 1882 contó como representante a

\footnotetext{
10 Tchernoff (1922), pp. $32-34$ y 92-94, y Bagehot (1922), pp. 265-275.

"Baldy (1.922), pp. 20-25.

12 ADP, carpeta 2000, telegrama de Paribas, 29-1-1886.

$3 A D P$, carpeta 2111 , contrato del empréstito ley del 25-10-83.
} 
Mallmann y Compañia. Al igual que Bemberg, era una de las firmas más importantes de Buenos Aires dedicadas a operaciones de comercio exterior.

Debido a las dificultades para colocar los títulos exclusivamente en el mercado de París, los grupos franceses se asociaron siempre con bancos británicos, por cuyo intermedio buscaron asegurarse el acceso a Londres. Así, pues, el grupo Paribas recurrió sucesivamente a Murrieta, Morton Rose y Baring para los empréstitos de Ferrocarriles, Tesorería y Banco Nacional, mientras que el de Générale se unió con Morgan para el de Obras I. En todos los casos los bancos ingleses se limitaron a intervenir como agentes de emisión, excepto en el último empréstito (Obras II) en que Baring y Morgan integraron también el sindicato contratista, como preludio del desplazamiento de los grupos franceses que sobrevendría después.

\section{El empréstito de Ferrocarriles y la entrada de los grupos franceses}

El empréstito de Ferrocarriles constituyó el punto de partida de la inversión de los capitales franceses en la Argentina. Tomado por el grupo Paribas en marzo de 1881, su negociación marcó un viraje en la política de endeudamiento externo del Gobierno argentino. A diferencia de lo ocurrido hasta entonces, en que el Gobierno había dirigido sus requerimientos de fondos exclusivamente al mercado británico, en esta oportunidad procuró ampliar el espectro de alternativas de financiación. A tal efecto implementó por primera vez un sistema de licitación para la adjudicación del empréstito, que posibilitó la participación de nuevas firmas procedentes de otras plazas.

Este cambio de política fue estimulado por la propia actitud de los banqueros franceses, que, a través de sus continuas propuestas de los años precedentes, habían puesto de manifiesto su interés por participar en esta esfera de negocios. Al proponer este empréstito, el senador Civit informaba:

El Poder Ejecutivo no se verá obligado a contratar solamente en Inglaterra este empréstito, puesto que tiene la Francia que empieza a hacer competencia, lo que es un gran beneficio para este país que tantas obras tiene que hacer... El año pasado un representante de una casa fuerte de Francia se presentó al gobierno ofreciéndole 300 millones de francos para liquidar las diferentes series de nuestra deuda interna y esterna [sic.] Conferencié una vez con el agente [¿Heimendahl? ] y este señor me decía: «la República Argentina necesita ferrocarriles y si no se hace la negociación en la suma que proponemos, podrá el capital francés venir a hacer competencia al inglés, y entonces prestaremos, en muy 
buenas condiciones, 15 ó 20 millones de [pesos] fuertes para que se complete la construcción de Ferrocarriles... ${ }^{14}$.

En la negociación del empréstito compitieron principalmente dos firmas británicas, Baring y Stern, y dos grupos franceses, conducidos por Paribas y Générale ${ }^{15}$. La situación se planteó en términos favorables a los banqueros franceses por la decisión del Gobierno de exigir la contratación en firme, más adecuada a su modalidad operativa que a la de los bancos ingleses. Esto motivó la retirada del principal proponente de ese origen, Baring, mientras que el otro, Stern, no pudo equiparar los términos de las ofertas francesas. La disputa final quedó entonces circunscripta a los dos grupos franceses, y se resolvió, en un desenlace confuso, a favor de Paribas ${ }^{16}$.

El grupo de Paribas logró obtener el empréstito a un precio bastante bajo, equivalente al 82 por 100 del valor nominal, en momentos en que otros títulos similares se cotizaron en Londres a un 92.93 por 100 . Este bajo precio motivó severas críticas de los medios de prensa locales, que lo atribuyeron al sistema de contratación en firme adoptado por el Gobierno. Sin embargo, la propuesta de Baring para emitir por cuenta y riesgo del Gobierno no había sido mucho más alta: apenas representaba el 85 por 100 del valor nominal. En realidad, la misma circunstancia que parece haber impulsado al Gobierno a optar por este sistema (la incertidumbre prevaleciente en la situación politica externa) sirve para explicar el amplio margen que los banqueros se reservaron sobre las cotizaciones ${ }^{17}$. De cualquier manera, el grupo francés se vio favorecido por este sistema, ya que pudo realizar la emisión, dos meses después, al 91 por 100. Descontando los gastos de emisión y sellado, que corrían a su cargo (aproximadamente un 1 por 100 ), obtuvo un beneficio del 8 por 100 .

${ }^{14} \mathrm{El}$ testimonio adquiere relevancia, además, por las vinculaciones de ese personaje con la Administración entrante del general Roca (DSCS, 28-9-1880, p. 262). En la misma sesión, el ministro del Interior informaba sobre otra propuesta de un grupo industrial francés, Scbneider, para financiar los ferrocarriles mediante el mecanismo del crédito de proveedores (DSCS, 28-9-80, pp. 266-267). Asimismo, encontramos testimonios de propuestas anteriores en $A V P, 4-7-14$ (1878) y 5-1-1 (1879), y una referencia retrospectiva en L'Economiste Français, 22-9-1888, p. 353.

15 Jones (1972), p. 3, cita referencias a la intervención de otras firmas, que consideramos que tuvieron una participación marginal o bien fueron incluidas erróneamente: Murrieta (agente de emisión de Paribas), Heine (socio habitual de Caben), Erlanger (de Londres) e Ibáñez Vega (de París).

${ }_{16}$ El representante de Générale, Carlos Pellegrini, protestó públicamente porque no se le concedió oportunidad para mejorar su propuesta, como, en cambio, se hizo con Heimendahl, el agente del grupo Paribas (La Nación, 25-3-1881). Diversos medios insinuaron la existencia de compromisos previos con este último (La Prensa y La Tribuna Argentina, 29-3-1881).

$"$ La Tribuna Argentina, 30-3-1881: «... se dice que tal vez exigencias de la política exterior han obligado al Gobierno a proceder como lo ha hecho... La noticia no puede 
La modalidad implementada para la entrega de los fondos, tanto en este como en los siguientes empréstitos, implicó una fuente adicional de beneficios. Como los fondos se ponían a disposición del Gobierno bajo la forma de letras pagaderas a los noventa días de su aceptación, transcurrían por lo menos cuatro meses hasta que los banqueros debían abonarlas (el transporte de Buenos Aires a París demandaba unos treinta días), lapso en el cual percibían los intereses. Además, cobraban una comisión de 1.3 por 100 por la aceptación de los giros.

Con el fin de minimizar los riesgos que implicaba la colocación de los títulos en un nuevo mercado, los contratistas realizaron la emisión simultáneamente en París y en Londres. Para ello se asociaron con Murrieta, que contaba con una importante clientela en esa plaza por haber emitido el último empréstito argentino («Obras Públicas» de 1871). La publicidad hizo hincapié en este aspecto, así como también en el hecho de que el nuevo empréstito era una continuación del de 1871.

El interés del sindicato por colocar una parte de la emisión en Londres se reflejó también en una cláusula del contrato por la que condicionaba toda la operación a que se lograra la admisión de los títulos en el Stock Exchange. Para su cumplimiento, el Gobierno debió ceder posiciones en un conflicto que sostenía con una compañía ferroviaria británica por el pago de intereses garantizados ${ }^{18}$. El incidente puso tempranamente de manifiesto las limitaciones de este intento de recurrir a la banca francesa como una fuente de financiación alternativa del mercado de Londres.

Los resultados de la emisión fueron muy favorables. En París los pedidos superaron dieciocho veces la cantidad de títulos ofrecidos, y en Londres unas veinte veces ${ }^{19}$. De acuerdo a estas magnitudes podemos evaluar que un 47,5 por 100 se colocó en la primera plaza y un 52,5 por 100 en la segunda. Estas cifras son, sin embargo, provisorias. Según la práctica habitual, los títulos eran tomados en gran parte por los propios banqueros y otros intermediarios, y recién llegaban a sus destinatarios finales (el público ahorrista) al cabo de unos meses ${ }^{20}$.

hacer muy buen efecto a los negociadores del empréstito, porque si lo lanzan como un empréstito de guerra muy pocos tomadores tendrám. Las condiciones de contratación y emisión figuran en $A D P$, carpeta 2088, Bases propuestas el 18-3.81 y prospectus de emisión del 27-5-81. Las cotizaciones de los títulos argentinos en Londres han sido extraídas de The Statist, $26-3$ y 2-4-81, pp. 328 y 356.

1" $A D P$, carpeta 2088, telegrama de Balcarce a Cortínez, 19-5-81. La compañía en cuestión era el Ferrocarril Argentino del Este, que ya había logrado obstruir la cotización en Londres de otros títulos del Gobierno (The Statist, 25-3-81, p. 328).

19 ADP, carpeta 2088, telegrama de Balcarce a Cortínez, 4-6-81, y The Statist, 4-6-81, p. 612 .

${ }^{20}$ Diversos comentarios periodísticos aludían a esta práctica: The Economist, 18-2-82, anexo, pp. 5-7, y L'Economiste Français, 16-4-87, p. 488. 
Precisamente en el período en que esta colocación definitiva debía tener lugar, la situación del mercado francés comenzó a deteriorarse. El proceso de alza general de las cotizaciones iniciado en 1879 se interrumpió hacia mediados de 1881 , y dio paso a una tendencia descendente. Como resultado de esto, un gran número de valores internacionales (cotizados en varias plazas) comenzó a ser transferido hacia Londres ${ }^{21}$. Es razonable suponer que una porción apreciable de los títulos de Ferrocarriles se incorporó a este flujo, por lo que estimamos que la parte retenida en el mercado francés no debió superar la mitad del porcentaje original. En consecuencia, el intento de los banqueros franceses de crear un mercado de valores argentinos en París sólo se pudo cumplir parcialmente con esta operación.

\section{Los empréstitos posteriores y las limitaciones de la inversión francesa}

Luego del empréstito de Ferrocarriles, el grupo francés de Paribas continuó siendo el interlocutor preferencial del Gobierno argentino. Hasta 1884 ese grupo, y luego Générale, tomaron a su cargo las sucesivas operaciones que el Gobierno debió realizar para proseguir su programa de obras públicas y atender otros objetos diversos. Esta posición predominante se ejerció en condiciones muy peculiares. El agravamiento de la situación del mercado francés, que en enero de 1882 experimentó una profunda crisis, prolongada hasta 1886, agudizó la dependencia de los banqueros franceses respecto del mercado británico para la colocación de los empréstitos. Cuando la situación de Londres comenzó también a deteriorarse, resultó evidente que su intervención no aportaba ninguna nueva alternativa y sólo redundaba en mayores costos para el Gobierno:

En este sentido puede decirse que volvemos al negocio «del tío Bartolo» pues en lugar de ir a Londres directamente a negociar los títulos, vamos a París para que los franceses nos cobren una buena comisión y los lleven a los ingleses que son siempre los que tienen capitales disponibles para esta clase de operaciones y que a su turno cobren otra comisión, todo lo que se traduce en menos precio que obtenemos por aceptar estas intervenciones estrañas ${ }^{22}$.

En un principio, Paribas pudo mejorar sensiblemente las condiciones que había ofrecido por el empréstito de Ferrocarriles. Así, pues, en octubre de 1882 tomó el pequeño empréstito de «Billetes de Tesorería» al 90,5 por 100

${ }^{21}$ The Economist, 18-6, 9-7, 16-7 y 29-10-1881, pp. 761, 861, 891 y 1341.

${ }^{22}$ Ezequiel Paz, en DSCD, 9-6-1884, p. 226. 
de su valor nominal, con un costo financiero para el Gobierno del 6,6 por 100 anual, en vez del 7,3 por 100 de la operación anterior. No obstante, apenas logró obtener por la emisión un 92,5 por 100 , es decir, lo mínimo indispensable para cubrir sus gastos y remunerar a los intermediarios. Para la colocación de los títulos recurrió a la firma británica Morton Rose, que acababa de emitir un empréstito de la provincia de Buenos Aires. Debido a la catástrófica situación del mercado de París, la operación se realizó exclusivamente sobre Londres, pero los resultados en esta plaza, igualmente, fueron muy pobres, y una importante cantidad de títulos quedó transitoriamente en la cartera de los banqueros franceses ${ }^{23}$.

A comienzos de 1883 el mismo grupo tomó un tercer empréstito, denominado «Banco Nacional», que el Gobierno había entregado a dicha entidad semioficial para solventar el aumento de su capital. La operación fue inicialmente disputada por Générale, cuyo nuevo agente Mallmann integraba el directorio de la institución. Este empréstito presentó la peculiaridad de ser el primero con un rendimiento nominal del 5 por 100 , frente al 6 por 100 de los empréstitos anteriores. Probablemente por esta circunstancia, y por los magros resultados obtenidos últimamente, los contratistas evitaron asumir el mismo grado de compromiso que en los casos previos. En vez de contratar inmediatamente en firme otorgaron un adelanto equivalente a dos tercios del producto neto, y tomaron una opción de un año por el empréstito que les permitía retirarse si la situación de los mercados no resultaba propicia.

Otro aspecto peculiar de esta operación fue la forma engorrosa en que se definió el precio de los títulos para el caso en que los contratistas levantaran la ópción. Diversos autores han considerado que éste fue el empréstito menos oneroso negociado en el período, basándose en el tipo de 85 por 100 estipulado en el contrato. Sin embargo, han omitido considerar los plazos legales contemplados para la entrega de los fondos (12 cuotas trimestrales), que los banqueros descontaron a razón del 5 por 100 anual al vencimiento de la opción. De esta manera, el producto neto se redujo a un 79,6 por 100 del valor nominal del empréstito ${ }^{24}$.

En septiembre de 1883 los banqueros aceptaron levantar la opción a su vencimiento, y obtuvieron la contratación de un nuevo empréstito de 5 por 100 , «Obras de Salubridad y Puerto de Riachuelo». Nuevamente eludieron asumir una completa responsabilidad, esta vez mediante el procedimiento de

${ }^{23}$ Agote (1884), pp. 9 y 10, y The Economist, 16-12-82, p. 1565. Sobre los magros resultados, Jones (1972), p. 6.

${ }^{24}$ Las condiciones completas figuran en la memoria del Banco Nacional inserta en Ministerio de Hacienda (1884), tomo II, pp. 19-22. La opinión optimista fue expresada por De Guerrico (1886), p. 23. En cambio, en los debates parlamentarios, el diputado Paz se opuso a la negociación por considerar que las condiciones etan leoninas (DSCD, 18-6-83, p. 335) 
tomar en firme sólo un tercio del empréstito. Como tenían el propósito de emitirlo conjuntamente con el del Banco Nacional, estipularon un precio similar al de este último. En cuanto al saldo no tomado en firme, quedaron en libertad para emitirlo por cuenta y riesgo del Gobierno, con una emisión de 2,5 por 100 más la mitad de lo que obtuvieran por encima del precio mínimo de 82,5 por 100 .

Fue éste el momento de mayor auge de las actividades de Paribas en la Argentina, pues casi simultáneamente dicho grupo obtuvo un importante empréstito de la provincia de Buenos Aires, por más de 11 millones de pesos/ oro ${ }^{25}$. Poco después comenzaría a afrontar dificultades, al abordar la etapa de la colocación de los títulos. En noviembre logró emitir el empréstito provincial, nuevamente por intermedio de Morton Rose, pero no pudo hacer lo mismo con los empréstitos nacionales a raíz de un conflicto con la firma Stern. Esta última cuestionó las garantías de «Salubridad y Riachuelo», por entender que afectaban las de un empréstito que había contratado anteriormente con la provincia de Buenos Aires. Ambas operaciones incluían una hipoteca sobre el puerto del Riachuelo, que en el ínterin había pasado de la jurisdicción provincial a la nacional ${ }^{26}$.

Mientras este conflicto se dilucidaba, Paribas encaró la colocación del empréstito del Banco Nacional en forma separada. Como la situación en Londres se había vuelto poco propicia para las nuevas emisiones, debió recurrir a Baring, que, por disponer de la principal clientela de títulos argentinos, era el que se hallaba en mejores condiciones para preparar el mercado. La emisión se concretó a fines de marzo de 1884 al precio de 84,5 por 100 , y, descontados los gastos, dejó un 4,9 por 100 a los banqueros participantes. Si bien se efectuó solamente en Londres, los banqueros franceses se reservaron una fracción de títulos para colocar en París cuando la situación se restableciera, que hemos estimado en alrededor de un 20 por $100^{27}$.

Entre tanto, el Gobierno, cada vez más acuciado por la necesidad de fondos para proseguir las obras públicas, había creado un nuevo empréstito (Obras I) por un monto muy superior a los anteriores (30 millones de pesos/ oro). Ante las limitaciones que evidenciaba el grupo francés de Paribas intentó negociarlo directamente con la banca británica, pero sus primeras gestiones

${ }^{23}$ Arena de Tejedor (1984), pp. 882-883. pp. 8 y ss.

${ }^{26}$ Ministerio de Hacienda (1883), pp. 69-71; AVP, 5-6-5, fol. 205; Agote (1885),

${ }^{27}$ Hemos calculado este porcentaje en base a los resultados de la primera serie de Obras II, emitida en enero de 1886, cuando todavía no se habían superado los efectos depresivos de la crisis de 1882 . La cotización en París fue conseguida el 27 de agosto (Revue Sud-Américaine, 15-9-1884, p. 112). Sobre la emisión en Londres, véanse The Economist, 29-3 y 5-4-1884, pp. 383 y 423, y The Statist, 29-3-1884, p. 370. La realización de una larga tarea preparatoria del mercado fue revelada por el ministro Plaza ( $D S C D$, 6-6-1884, p. 222). 
ante Baring resultaron infructuosas. Esto posibilitó la entrada en el negocio del otro grupo francés, el de Générale, que se asoció con la prestigiosa firma británica J. S. Morgan y ofreció realizar toda la emisión por intermedio de la misma.

Al igual que Paribas en su último empréstito, este nuevo grupo sólo accedió a tomar en firme un tercio de los títulos. En cuanto al precio, si bien se fijó en un 81,5 por 100, por la forma de entrega de los fondos (12 cuotas mensuales) quedó reducido a un 78,3 por 100 , inferior a las operaciones anteriores. Esta parte firme se emitió en septiembre de 1884 al 84 por 100 , lo que dejaba a los contratistas un margen de ganancias del 4,9 por 100. Sin embargo, la coyuntura para la colocación de títulos argentinos había seguido desmejorando y la banca Morgan no disponía de una fuerte clientela en ese sector del mercado como para poder revertir la situación. En consecuencia, la emisión fue un fracaso y casi todos los títulos quedaron sin vender ${ }^{28}$.

Hacia finales de 1884, la emisión de los saldos de los empréstitos de Salubridad y de Obras I había entrado en una vía muerta. Además de la situación del mercado, también influía la rivalidad entre ambos grupos, agudizada por haber tomado los empréstitos a precios distintos, y el hecho de no haberse comprometido a emitir en un plazo determinado. Como expresaba Carlos Pellegrini:

Ninguno de los dos sindicatos ha de permitir que el otro emita primero, teniendo ambos fuerza para ello. Lo que conviene a los dos es dejar las cosas como están, esperar un año o dos, entretanto van gozando el interés de nuestros fondos, hasta que llegue el buen momento y puedan realizar los ventajosos contratos que tienen ${ }^{29}$.

La crisis de 1885 y la renegociación de los empréstitos: ¿un triunfo del Gobierno o de los banqueros?

La suspensión indefinida de la emisión de los saldos de Salubridad y de Obras I puede considerarse como una de las causas de la severa crisis de cambios que sobrevino en la plaza porteña hacia fines de 1884 y que obligó al Gobierno a decretar la inconversión del papel moneda en enero de 1885 .

En el desencadenamiento de esta crisis se han señalado diversos factores. Algunos autores han destacado el desproporcionado aumento de importaciones

2 Sobre las condiciones de contratación y emisión, $A D P$, carpeta 2111 , contrato del emprestito, y The Statist, 6 y 13-9.84, pp. 258 y 308. Sobre el fracaso de la emisión y sus causas, véase el informe de Pellegrini, en DSCD, 20-10-85, pp. 666-670. También, De Guerrico (1886), pp. 61.62, y Jones (1972), p. 9.

2) Pellegrini a W. Pacheco, 4-5.1885, en ADP, carpeta 2096. 
del segundo semestre de 1884, atribuido, a su vez, al anuncio anticipado de las nuevas tarifas aduaneras de 1885 . Otros, como Williams, señalaron la incidencia del elevado servicio de los capitales extranjeros invertidos en el país. También se ha mencionado el creciente déficit fiscal, ocasionado, según Terry, por los grandes gastos extraordinarios que se autorizaban sin ninguna previsión de recursos ${ }^{30}$.

Por nuestra parte, hemos encontrado que una porción considerable del déficit fiscal provino de la ejecución de obras públicas, cuya financiación dependía de los empréstitos a que hemos aludido. En el cuadro 3 podemos observar que los gastos con cargo a estos empréstitos ya habían tomado importancia en 1882, cuando todavía no se habían negociado los títulos de Salubridad y de Obras I. Al cerrar el ejercicio de 1884 se había efectuado el 81 por 100 de los gastos, pero sólo había ingresado el 37 por 100 de los fondos (para el movimiento de los ingresos, véase el cuadro 2). Esta precaria

\section{CUADRO 2}

Empréstitos contratados por bancos franceses. Disposición de fondos, 1881-1887

\begin{tabular}{|c|c|c|c|c|}
\hline \multirow[b]{2}{*}{ Empréstitos } & \multicolumn{4}{|c|}{ LIBRAMIENTOS } \\
\hline & Fecha & $\begin{array}{c}\text { Monto } \\
\text { (pesos/oro) }\end{array}$ & $\begin{array}{l}\text { Interés } \\
(\mathscr{\%})\end{array}$ & Concepto \\
\hline Ferrocarriles $\ldots \ldots \ldots$ & $\begin{array}{l}22-3-81 \\
28-5-81\end{array}$ & $\begin{array}{l}1.008 .000 \\
9.095 .028\end{array}$ & $\begin{array}{l}6 \\
6\end{array}$ & $\begin{array}{l}\text { Anticipo } \\
\text { Saldo }\end{array}$ \\
\hline Tesorería $\ldots \ldots \ldots \ldots$ & $11-10-82$ & 3.712 .968 & 6 & Total \\
\hline Banco Nacional ... ... & $\begin{array}{l}14-3-83 \\
28-6-83 \\
30-4-84\end{array}$ & $\begin{array}{l}2.000 .000 \\
2.800 .000 \\
1.954 .623\end{array}$ & $\begin{array}{l}6+1 \\
6+1 \\
5\end{array}$ & $\begin{array}{l}\text { Adelanto } \\
\text { Adelanto } \\
\text { Saldo }\end{array}$ \\
\hline $\begin{array}{llll}\text { Salubridad } & \ldots & \ldots & \ldots\end{array}$ & $\begin{array}{l}21-9-83 / \\
21-11-83\end{array}$ & 3.206 .000 & 5 & Parte firme \\
\hline Obras I $\ldots \ldots \ldots c c$ & $\begin{array}{c}1-6 / 1-7-84 \\
24-7-84 \\
1-8-84 / \\
1-2-85\end{array}$ & $\begin{array}{l}2.053 .800 \\
2.016 .000 \\
3.939 .375\end{array}$ & $\begin{array}{l}5 \\
6+2 \\
5\end{array}$ & $\begin{array}{l}\text { Cuotas parte firme } \\
\text { Adelanto } \\
\text { Cuotas parte firme }\end{array}$ \\
\hline Obras II $\ldots \ldots \ldots \ldots$ & $\begin{array}{c}\text { Dic. } 85 \\
\text { Enero } 86 \\
21-1.86 \\
8-2-87 / \\
27-3-87\end{array}$ & $\begin{array}{l}4.536 .000 \\
4.536 .000 \\
3.528 .000 \\
\\
6.390 .000\end{array}$ & $\begin{array}{l}6+1 \\
6+1 \\
5 \\
5\end{array}$ & $\begin{array}{l}\text { Adelanto } \\
\text { Adelanto } \\
\text { Saldo emisión 1." serie } \\
\text { Emisión 2." serie }\end{array}$ \\
\hline
\end{tabular}

FUENTES: Idem cuadro 1.

${ }^{30}$ Jones (1972), p. 9; The Economist, 17-1-85, pp. 66-67; Williams (1920), pp. 44-52; Terry (1893), p. 63. 


\section{CUADRO 3}

Movimiento de ingresos y gastos correspondientes a los empréstitos destinados a obras públicas, 1881-1887

(En miles de pesos/oro)

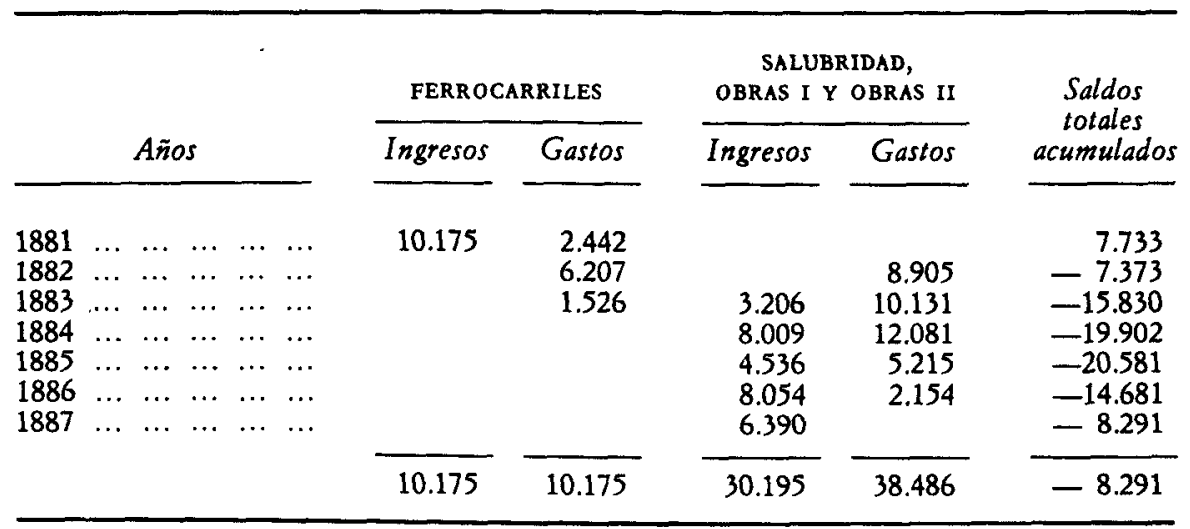

FuENTES: Idem cuadro 1.

situación de las finanzas públicas nos permite entender la débil posición del Gobierno en la negociación de los empréstitos, y las condiciones aún más desfavorables en que tuvo que renegociar la emisión de los saldos pendientes.

Uno de los recursos con los que el Gobierno afrontó inicialmente la demora en las emisiones fue el crédito de corto plazo de los bancos europeos. En el cuadro 4 se puede advertir que su magnitud fue aumentando en directa relación con el defasaje entre gastos e ingresos. Entre los diversos préstamos podemos diferenciar los adelantos sobre empréstitos, de significación sólo ocasional, y los créditos en cuenta corriente y giros, que entre 1883 y 1885 ayudaron a compensar las demoras en el ingreso de fondos de los empréstitos ${ }^{31}$.

Sin embargo, hacia fines de 1884 y comienzos de 1885 , estas fuentes de financiación no alcanzaron a cubrir los defasajes y el Gobierno debió apelar, en una escala sin precedentes, a los créditos del Banco Nacional. Esto generó una intensa presión sobre el mercado local, cuyos recursos eran de por sí li-

${ }^{31}$ Cabe destacar que la mitad de los créditos de cuenta corriente fueron otorgados por Comptoir, uno de los miembros del grupo Paribas, a través de una cuenta que abrió en 1882. Hasta su cierre, en 1889 , canalizó el 40 por 100 del movimiento de las cuentas de pagos del Gobierno argentino. Esta cuestión ha sido analizada en nuestro trabajo, inédito, "Los bancos franceses y los créditos al Gobierno argentino". 


\title{
CUADRO 4
}

\begin{abstract}
Créditos de corto plazo otorgados al Gobierno nacional por los bancos europeos y el Banco Nacional. 1882-1887

(En miles de pesos/oro)
\end{abstract}

\begin{tabular}{l|l|l|lll}
\multicolumn{5}{c}{ Saldos anuales acumulados } \\
\hline 1882 & 1883 & 1884 & 1885 & 1886 & 1887 \\
\hline
\end{tabular}

a) Bancos europeos:

Créditos en cuenta corriente $y$ por giros $\ldots \ldots \ldots \ldots \ldots \ldots$

Adelantos sobre empréstitos .........

$\begin{array}{llllllllllll}\text { Total crédito externo } & \ldots & \ldots & \ldots & \ldots & 865 & 6.100 & 9.615 & 8.104 & 6.378 & 6.899\end{array}$

b) Banco Nacional:

Créditos por giros y cuenta corriente.

$\begin{array}{llllll}865 & 6.100 & 6.825 & 8.104 & 3.858 & 6.899\end{array}$

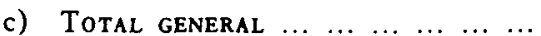

$\frac{1}{865} \frac{1.540}{7.640} \frac{5.372}{14.987} \frac{17.195}{25.299} \frac{8.171}{14.549} \frac{2.893}{9.679}$

FuEnTEs: Datos extraídos del Estado de Recursos y Erogaciones y del Estado de las cuentas corrientes en Europa, en Ministerio de Hacienda (1882-87).

mitados, y contribuyó de tal manera al estallido de la crisis financiera y de cambios.

La gravedad de la situación llevó al Gobierno a intentar a todo trance desbloquear las negociaciones. Más aún, lo ayudó a decidirse por el restablecimiento de sus antiguas relaciones con los banqueros británicos, tendencia ya insinuada en ocasión del empréstito de Obras I. Con tales propósitos, en marzo de 1885 fue comisionado a Europa el influyente ex ministro Pellegrini. Su objetivo inmediato era obtener un adelanto de Baring que permitiera sortear la crisis fiscal, pero como éste exigía un arreglo previo con los anteriores contratistas y con Morgan, se arribó finalmente a la formación de un nuevo sindicato que incluyó a todas esas firmas ${ }^{32}$.

Los banqueros, aprovechando la acuciante necesidad de fondos del Gobierno, impusieron nuevas exigencias. No sólo evitaron asumir nuevos compromisos, sino que, además, se desligaron de los que ya habían tomado por las partes firmes de Salubridad y Obras I. Dichas partes quedaban convertidas

${ }^{32}$ El Gobierno necesitaba unos 12 millones de pesos/oro: la mitad para las obras públicas y el resto para reembolsar los créditos europeos y del Banco Nacional (Pacheco a Pellegrini, 18-4-1885, en $A D F$, carpeta 2096). 
en adelantos reembolsables con un nuevo empréstito (Obras II) o, en caso de fracasar la emisión, con las propias rentas oficiales.

La exigencia más discutida fue la de una garantía especial sobre los ingresos de aduana. Esto daba al empréstito un derecho de preferencia sobre las demás deudas del Estado, puesto que esos ingresos representaban entre un 80 y un 90 por 100 de las rentas generales. Los banqueros buscaban así facilitar su colocación entre el público, comprometida por el fracaso de la última emisión, y, asimismo, evitar que fuera perturbada en caso de que el Gobierno contratara nuevos empréstitos a menor precio (como había sucedido con Obras I).

El ministro de Hacienda, Wenceslao Pacheco, encabezó la oposición a esta cláusula:

... si ahora se diese esa garantía quedarían primero perjudicados los títulos de deuda en circulación y coartada la libertad del Gobierno para deudas futuras. Hasta hoy nadie ha pedido esa garantía especial y por eso el Gobierno la juzga indecorosa y difícil de ser aceptada por el Congreso ${ }^{33}$.

En contraposición, Pellegrini consideraba que sería exigida por cualquier banquero al que se llevara el negocio y que, además, ello insumiría demasiado tiempo. Mientras tanto podría reagravarse la crisis:

Los que presumen más conveniente no hacer nada ni sospechan la situación en que será colocado el país aquí y allá ${ }^{34}$.

En efecto, luego de haber rechazado un primer contrato en agosto, el Gobierno debió reabrir las negociaciones y firmar un nuevo contrato en diciembre de 1885, ambos con dicha cláusula. El segundo contrato ha dado lugar a algunas confusiones. Evidenciando no haber cotejado los textos, Jones ha sostenido que sus condiciones eran mucho más benignas para el Gobierno. Sin embargo, un somero examen permite advertir que los contenidos eran sustancialmente idénticos. Precisamente las severas condiciones impuestas permitieron a los banqueros retomar los elevados rendimientos de sus primeras operaciones ${ }^{35}$.

${ }^{33}$ Pacheco a Pellegrini, 18-5-85, en $A D P$, carpeta 2096.

34 Pellegrini a Pacheco, 10-7-85, en $A D P$, carpeta 2096.

33 Las apreciaciones de Jones (1972), p. 12, lo llevan a concluir que el Gobierno mantuvo una posición negociadora más sólida que los banqueros, contrariamente a lo que hemos podido observar. Además, aunque la ejecución de la garantía quedaba a cargo del Banco Nacional, es discutible que esto bastara para desligar al Gobierno del compromiso, como llegó a sostener el ministro Hansen tras la liquidación de ese banco: Ministerio de Hacienda (1891), tomo I, p. 216. Otra cláusula onerosa era la que fijaba las comisiones 
El empréstito se emitió simultáneamente en Londres y en París, en dos series sucesivas. La primera se colocó en enero de 1886 al 80 por 100 , y reportó a los contratistas una comisión del 5 por 100 . Al cabo de un año se emitió la segunda, esta vez al precio de 85,5 por 100 , como resultado de la mejoría de la situación de los mercados financieros y del crédito argentino en particular. La comisión de los banqueros se elevó entonces al 7,75 por 100 , cifra similar a la del empréstito de Ferrocarriles, que había sido hasta el momento la operación más rentable.

El Gobierno sólo recibió por este empréstito el 76 por 100 del monto nominal. De esos fondos, la mayor parte fue retenida por los contratistas para reembolsar adelantos que habían otorgado al Gobierno con anterioridad. Tal es así que las sumas, efectivamente, entregadas ascendieron a unos 7.285.000 pesos/oro, frente a un producto neto de unos $31.800 .000^{36}$. Ese fue el precio que el Gobierno debió pagar para recobrar el acceso a las fuentes de financiación externa.

La parte suscrita en Francia ascendió en la primera serie a un 20 por 100 , y en la segunda a un 40 por 100 . De tal manera, esta operación permitió a los banqueros completar el proceso iniciado en 1881, de conformación de un mercado de valores argentinos en París. Sin embargo, también marcó el final de su predominio en el campo de los empréstitos públicos nacionales. Al dejar nuevamente en libertad de acción al Gobierno argentino pudo éste concretar su reaproximación a los banqueros británicos, como así también iniciar tratos con un nuevo grupo, integrado por los grandes bancos alemanes. Ambos compartirían en lo sucesivo la preponderancia en esta esfera de negocios, en la que los franceses no tendrían ocasión de reingresar.

\section{El destino de los capitales invertidos: exportación de capitales $y$ exportación de mercancias}

Si bien nuestro objeto de estudio es la actividad de los grupos inversores franceses, resulta interesante examinar el destino que el Gobierno argentino dio a los fondos, pues ello nos permite indagar sobre las posibles conexiones de estas operaciones con otros negocios emprendidos por los grupos franceses.

de los banqueros, que consistían en el 2,5 por 100 del valor nominal del empréstito, más la mitad del excedente que obtuvieran en la emisión por encima del 75 por 100 , precio muy inferior al de los empréstitos anteriores (ADP, carpetas 2096 y 2097). Ferns (1966), p. 403, ha comentado: «El acuerdo tenía el carácter de un Tratado. Las cláusulas de introducción estaban redactadas en el estilo del derecho internacional.» Sin embargo, la redacción era similar a la de cualquier empréstito anterior.

${ }^{36}$ Según la liquidación oficial que aparece en Ministerio de Hacienda (1886), tomo I, pp. LIII-LIV. 
Particularmente nos interesa verificar si en el caso de los empréstitos de obras públicas se cumplió la controvertida tesis de que las inversiones externas constituyeron una herramienta para favorecer las exportaciones de mercancías por parte de empresas del mismo país inversor. Sobre esta cuestión, a fines de 1880, el periódico londinense The South American Journal comentaba:

Los franceses están tomando ahora una gran participación en los negocios de ferrocarriles que primitivamente se derivaban hacia los mercados ingleses, y encuentran una salida más rentable para sus capitales excedentes compitiendo exitosamente con nuestros fabricantes en la exportación de rieles y materiales para la construcción de ferrocarriles ${ }^{37}$.

Este comentario aludia indirectamente al nuevo empréstito argentino de $\mathrm{Fe}$ rrocarriles que se acababa de autorizar, y se basaba en una nota del diario británico de Buenos Aires The Standard, que anunciaba:

Los bonos ferroviarios propuestos probablemente no lleguen al mercado de Londres, desde que hay firmas francesas ansiosas por contratar las obras y recibir los bonos en pago ${ }^{38}$.

En esa misma línea la memoria de 1881 del Ministerio del Interior, al referirse a las obras financiadas con el empréstito, informaba sobre una importante cantidad de rieles y material ferroviario provistos por la empresa Schneider. Basándose en dicha información, Carlos Marichal ha sostenido en un artículo reciente que los banqueros franceses supieron aprovechar los empréstitos para promover la exportación de una cantidad nada despreciable de bienes de capital al Río de la Plata, particularmente para las obras del ferrocarril "Central Norte», y que varias fuertes empresas industriales francesas estuvieron interesadas en el negocio ${ }^{39}$.

Afortunadamente, hemos podido localizar una detallada rendición de cuentas de los gastos de construcción ferroviaria imputados a los empréstitos de obras públicas, así como también algunos de los más importantes contratos celebrados para la provisión de materiales en ese período ${ }^{40}$. Es así como hemos podido determinar que la importante operación mencionada en la memoria de Interior (de 700.559 pesos/oro) fue obtenida por Schneider en marzo de

37 The South American Journal, 25-11-1880, p. 12.

3t The Standard, 14-9-188, p. 2, col. 4.

3y Marichal (1984), pp. 61-62; Ministerio del Interior (1881), pp. XXIV-XXV.

4 Departamento de Obras Públicas (1884), pp. 64 y ss.; Registro Nacional (1880), pp. $114-118$; (1881), p. 95 ; (1883-I), p. 44; (1883-II), pp. 145,149 y 210; (1884-I), pp. 472,577 y 580 ; (1884-II), p. 46. 
1880, es decir, un año antes de la contratación del empréstito de Ferrocarriles por los banqueros franceses. En ese entonces, el grupo Schneider todavía mantenía negociaciones para tomar a su cargo la financiación de las construcciones ferroviarias a cambio de la adjudicación de los materiales, aunque ya se había frustrado un primer acuerdo y por eso la operación se hizo al contado. Más tarde, sin embargo, sus posibilidades se vieron cortadas por la política del nuevo Gobierno de separar los aspectos financieros y comerciales de estas operaciones, y por la escasa competitividad de sus precios frente a las firmas británicas ${ }^{41}$. En un principio, tampoco los banqueros que tomaron los em. préstitos pudieron sacar provecho del flujo de fondos destinado a los materiales, pues el Gobierno los hizo depositar en una cuenta de Baring, contra la cual libró los pagos. Asimismo, encargó casi todos los pedidos a las firmas británicas, más conocidas en el mercado argentino.

Esta situación favorable a las firmas británicas se revirtió a partir de 1883, cuando el Gobierno modificó el sistema de adjudicación y comenzó a practicar licitaciones locales, a la vez que encauzó la mayor parte de los fondos a través de los banqueros franceses. El sistema de licitación de los materiales, en cambio, no favoreció a los franceses, sino, principalmente, a empresas belgas y norteamericanas, hasta entonces poco conocidas en el mercado argentino. Schneider sólo obtuvo pedidos por 307.647 pesos/oro, casi todos en el rubro de estructuras metálicas, que tenía escasa significación en el conjunto de los materiales. Aun en ese campo, desde mediados de 1884, se vio superada por otras firmas, entre ellas la francesa Fives Lille.

Hacia mediados de 1885 los materiales recibidos del exterior sumaban unos 8.300 .000 pesos/oro, equivalentes a un 38,5 por 100 del total de gastos imputados (el resto correspondía a gastos dentro del país). La participación francesa apenas alcanzaba el 12,3 por 100 , mientras que las firmas británicas habían obtenido el 65,5 por 100, las norteamericanas el 14,5 por 100 y las belgas el 7,7 por $100^{42}$. Evidentemente, el papel de la industria francesa fue muy inferior al de la banca del mismo origen en la contratación de los respectivos empréstitos, y aun al del mercado de París, que absorbió alrededor de un 30 por 100 de las emisiones ${ }^{43}$. Por otra parte, los pedidos fran-

"1 El precio de los rieles provistos por Schneider en 1880 fue de 61 pesos/oro por tonelada, frente a los 48 y 40,5 cobrados por las firmas británicas Cammell y Bolkow en 1881 y 1883 , respectivamente, y a los 32 pesos de la belga Cockerill en 1884.

$42 \mathrm{~A}$ su vez, los gastos ferroviarios insumieron un 51,2 por 100 del producto de los empréstitos de obras públicas. Otro rubro importante fue el de las obras de salubridad de la ciudad de Buenos Aires, que absorbió el 26,2 por 100 de dichos fondos. En este caso no disponemos de una rendición detallada, pero sabemos que, por decisión de la comisión administradora, los materiales fueron encargados en Inglaterra por intermedio de Baring.

${ }^{3}$ Resulta interesante observar que la participación industrial británica coincidió bastante bien con la proporción de los títulos colocados en Londres (un 70 por 100). Esto 
ceses correspondieron casi totalmente a una sola firma, Scbneider, y en su mayor parte a una sola operación, la de 1880 . Por sus elevados costos, esta industria sólo podía haber aumentado su participación si hubiera conseguido condicionar de alguna manera la provisión de fondos a la de los materiales, pero los bancos franceses no tenían mayor interés en presionar en esa dirección. Tales procedimientos suponían, en general, un grado de interpenetración entre la banca y la gran industria que no se verificaba en el caso de Francia.

Esto no implicaba que quedara descartada una asociación ad hoc, como la que años más tarde llevaron a cabo el banco Paribas y la metalúrgica Fives Lille para la fundación de compañías ferroviarias en la Argentina. Semejante experiencia se pudo desarrollar en una peculiar coyuntura de auge financiero y estancamiento interno de la economía francesa, que llevó a ambas empresas a interesarse en dicha esfera de negocios como un medio para expandir sus respectivas actividades ${ }^{44}$. En este sentido, la exportación de capital sirvió, efectivamente, de herramienta para asegurar la exportación de mercancías. No obstante, hay que tener en cuenta que se trató de una inversión directa, mientras que las operaciones que hemos analizado fueron inversiones indirectas, en la que los grupos encargados de proveer los capitales carecieron de control sobre su inversión.

Para el análisis que acabamos de efectuar nos hemos basado, como quedó dicho, en las rendiciones oficiales de los gastos imputados a los empréstitos. Dichas rendiciones, sin embargo, no se correspondieron necesariamente con el uso real de los fondos. En algunos casos esos gastos ya se habían cubierto provisoriamente antes de la contratación de los empréstitos, mientras que en otros, inversamente, se trataba de gastos por efectuar en un lapso muy prolongado, durante el cual resultaba oneroso mantener inactivas sumas tan elevadas. Además, como el Gobierno recibía estos fondos bajo la forma de giros sobre el exterior, era lógico que los usara para cancelar compromisos externos y que luego transfiriera a la cuenta del empréstito las sumas equivalentes en moneda nacional. De tal manera evitaba recurrir al mercado local de cambios, donde una presión excesiva podía originar un alza en la cotización del oro y las divisas.

A pesar de estas consideraciones, el conocimiento de los rubros en que

parece ratificar las observaciones de Ford (1966), pp. 120-122, sobre el marcado paralelismo entre las exportaciones de capital y de bienes de inversión británicos hacia la Argen. tina. En el caso de los empréstitos estudiados, esta correspondencia puede explicarse sen. cillamente: tanto el mercado británico de capitales como la industria británica de material ferroviario mantuvieron una posición de liderazgo por su mayor capacidad operativa y sus menores costos. Pero también debemos señalar que esa correspondencia no se mantuvo a nivel de cifras anuales: la participación industrial alcanzó su grado más alto después del empréstito de Ferrocarriles y disminuyó en los años siguientes, precisamente cuando el papel de la plaza londinense se tornó más relevante.

" Hemos analizado esta experiencia en Regalsky (1985). 
se gastaron, efectivamente, los fondos no deja de tener utilidad, puesto que permitte apreciar algunos de los factores subyacentes en el origen de los empréstitos estudiados. Hemos podido realizar este análisis sobre una porción sustancial de los fondos, aquellos que el Gobierno no depositó en sus cuentas corrientes ante diversos bancos europeos entre 1881 y 1883 (el 63,9 por 100 de los empréstitos de Ferrocarriles, Billetes de Tesorería y parte firme de Salubridad). Del mismo se desprende que las compras de material ferroviario y de obras públicas, pese a su fuerte expansión en esta etapa, sólo absorbieron un 18,6 por 100 de los fondos, en tanto otro 9,6 por 100 se destinó a importaciones de metálico, y nada menos que el 63,6 por 100 se utilizó para pagar los servicios de la deuda externa.

Esta elevada proporción insumida por los servicios de la deuda nos muestra que ese rubro constituía, por su gran magnitud y carácter inelástico, la principal fuente de restricciones externas que afrontaba el Gobierno. Su incidencia se tornaba más crítica en una coyuntura como la que nos ocupa, en la que el sostenimiento de una política expansiva de obras públicas impedía recurrir a las fórmulas clásicas de ajuste. En tales circunstancias, al Gobierno sólo le quedaba la alternativa de recurrir masivamente a los empréstitos externos, de manera de asegurarse un flujo de fondos que operase como contrapartida del creciente drenaje que implicaban los servicios. En este sentido, este enfoque resulta convergente con las observaciones de Williams sobre la importancia de los desequilibrios entre el servicio de la deuda y la entrada de nuevos capitales como fuentes de las crisis argentinas de 1885 y 18904 .

\section{Consideraciones finales}

Podemos apreciar en el estudio realizado la particular incidencia de las cambiantes condiciones de los mercados financieros sobre el curso de las inversiones francesas. $\mathrm{La}$ introducción de los grupos franceses correspondió a una etapa de auge financiero en París, que generaba condiciones apropiadas para que los banqueros intentaran conformar un mercado de valores argentinos en esa plaza. Esto coincidió con el interés del Gobierno argentino por diversificar sus fuentes de financiación y reducir su dependencia del mercado de Londres. Sin embargo, este proyecto, iniciado auspiciosamente con el empréstito de Ferrocarriles, se vio frustrado por el estallido de la crisis de 1882, que sumergió al mercado de París en una completa atonía.

Bajo estas condiciones, no deja de ser sorprendente que los grupos franceses hayan podido mantener su predominio hasta 1885 , y, en tal sentido, el

45 Williams (1920), especialmente pp. 48, 105 y 112-113. 
factor primordial de su permanencia debe buscarse, sin duda, en su gran potencial financiero. En efecto, fue su capacidad para tomar en firme los empréstitos y para otorgar diversos créditos lo que les permitió seguir obteniendo los negocios, aunque para su emisión debieran recurrir a los bancos británicos, a fin de canalizar los títulos hacia el mercado de Londres. Esta contradicción entre su fortaleza para la contratación y su debilidad para la emisión es atribuible a los efectos de la crisis de 1882, que, al tiempo que limitó la capacidad del mercado de valores, estimuló la concentración en el sector financiero y permitió emerger a los grandes establecimientos con un mayor poderío.

De todos modos, las limitaciones de los grupos franceses en el plano de la emisión derivaron, finalmente, en su desplazamiento, lo que se evidenció en oportunidad del último empréstito cuando Baring volvió a erigirse en el interlocutor preferido del Gobierno. Paradójicamente, fue también con esta operación que los banqueros lograron conformar el mercado de valores argentinos en París, pues su realización coincidió con la reactivación de dicha plaza. Por eso el alejamiento de los grupos franceses de esta esfera de negocios no implicó su retirada de la Argentina, sino solamente su reorientación hacia nuevos rubros, con los cuales buscaron alimentar el nuevo mercado que habían creado: compañías ferroviarias, en el caso de Paribas, y empréstitos provinciales, en el de los demás bancos.

Otro aspecto interesante es el de las diversas modalidades de contratación que adoptaron los grupos franceses y su relación con el curso de las negociaciones. Es evidente que desde el primer empréstito de 1881, tomado totalmente en firme, hasta el de 1885 , emitido por cuenta del Gobierno, hubo una progresiva reducción de responsabilidades por parte de los banqueros. Esto se puede explicar por el mayor riesgo de las operaciones a partir del cambio de la coyuntura de 1882-83. Pero también se puede vincular con la modificación de la relación de fuerzas entre las partes negociadoras. En el primer empréstito la posición de los grupos franceses era más débil, pues intentaban acceder por primera vez a una esfera de negocios que hasta entonces había sido privativa del mercado de Londres. Para ello debían hacer ciertas concesiones en materia de riesgos y rentabilidad. En cambio, en las últimas operaciones su posición se había fortalecido, pues negociaban con un Gobierno apremiado por dificultades financieras, lo que les daba margen para disminuir su grado de responsabilidad y pactar precios más bajos. Incluso en el empréstito de 1885 pudieron condicionar la ejecución de los contra. tos pendientes a la modificación de sus cláusulas en un sentido aún más favorable.

Estos mismos elementos influyeron también en la evolución de los beneficios. En la primera operación los banqueros obtuvieron un elevado margen 
de utilidades como resultado de haber adoptado la contratación en firme en una coyuntura ascendente. Luego debieron reducirlo por las dificultades de emisión ante el deterioro de la coyuntura financiera. En la última operación recuperaron los niveles iniciales, bajo las nuevas condiciones que pudieron imponer al Gobierno después de la crisis argentina de 1885. Esta crisis se había originado en parte por las dificultades de los banqueros para emitir los empréstitos pendientes, así como por el creciente peso de los servicios de la deuda pública externa. En la medida en que contribuyó a erosionar la posición negociadora del Gobierno, constituyó la clave que permitió a los banqueros salir provechosamente del impasse.

Indudablemente, desde la perspectiva del Gobierno argentino, esta experiencia de buscar fuentes de financiación alternativa no dio los resultados que se esperaban. El intento de apostar a la competencia entre los distintos grupos financieros (desplazamiento de Paribas por Générale, y luego reorientación hacia Baring) no logró impedir que el costo financiero de los últimos empréstitos fuera creciente.

Finalmente, podemos considerar estas operaciones desde el punto de vista de la conexión entre exportaciones de capital y de mercancías, a fin de establecer en qué medida sirvieron para estimular la colocación de productos industriales franceses en la Argentina. En tal sentido hemos comprobado que, a pesar de que hubo una primera tentativa para combinar la financiación de las obras públicas con la provisión de los materiales, ambos aspectos de las operaciones se realizaron de manera independiente. La mayor parte de los fondos provistos por los banqueros franceses se canalizaron hacia empresas británicas, norteamericanas y belgas, en tanto la industria francesa quedó marginada por sus elevados costos. Por otra parte, el intento inicial de combinar ambos aspectos de las operaciones había sido efectuado por un grupo industrial, Scbneider, sin participación visible de los bancos franceses que tomaron luego los empréstitos. Una acción conjunta de ambos tipos de establecimientos habría requerido una comunidad de intereses que entonces no se verificaba, como tampoco se daba la necesaria correlación de fuerzas para imponer al Gobierno tales condicionamientos. Recién a fines de la década hubo una coincidencia entre firmas bancarias e industriales para la realización de nuevos negocios en la Argentina, que, a diferencia de los casos estudiados, se hicieron bajo la forma de inversiones directas. Podemos concluir, entonces, que la exportación de capitales franceses a la Argentina mediante empréstitos no estimuló la exportación de mercancías del mismo origen, y que esto sólo fue posible cuando los inversores adoptaron el procedimiento de las inversiones directas, el único que les permitió influir en el destino de los fondos aportados. 


\section{BIBLIOGRAFIA}

ADLER, John (ed.) (1967): Capital Movements and Economic Development, Nueva York, Macmillan.

ADP: Arcbivo de la Deuda Pública (Ministerio de Hacienda, República Argentina).

Agote, Pedro (1881-1887): Informe del Presidente del Crédito Público Nacional sobre la deuda pública, bancos y emisiones de papel moneda, Buenos Aires, 5 vols.

Amaral, Samuel (1984): «El empréstito de Londres de 1824*, Desarrollo Económico, 92, pp. 559-588.

ARENA DE TEJEDOR, Francesca (1984): «El ingreso de capitales extranjeros en el Gobierno del doctor Rochaw, VI Jornadas de Historia Económica Argentina, Vaquerias (Córdoba), pp. 872-884.

As H wORT H, William (1978): Breve bistoria de la economia internacional, Madrid, Fondo de Cultura Económica.

AVP: Archivo Victorino de la Plaza (Archivo General de la Nación, República Argentina, Sala 7).

BAGE H OT, Walter (1922): Lombard Street. A Description of the Money Market, Londres.

Baldy, Edmond (1922): Les Banques d'Affaires depuis 1900, París.

Bouvier, Jean (1968): «Recherches sur l'histoire des mécanismes bancaires en France au XIX siecle», Histoire économique et bistoire sociale, Ginebra, pp. 93-134.

Cameron, Rondo (1971): Francia y el desarrollo económico de Europa, 1800-1914, Madrid, Tecnos.

De GUERrICo, Alberto (1886): Finanzas argentinas. Estudios e ideas sobre nuestros empréstitos externos, Buenos Aires.

Departamento de Obras Públicas (1881-87): Memoria anual, Buenos Aires.

DSCD (1879-1887): Diario de Sesiones de la Cámara de Diputados, República Argentina, Buenos Aires.

DSCS (1879-1887): Diario de Sesiones de la Cámara de Senadores, República Argentina, Buenos Aires.

FeIs, Herber (1930): Europe the World Banker, Nueva York.

FERNs, H. S. (1966): Gran Bretaña y Argentina en el siglo XIX, Buenos Aires, SolarHachette.

FORD, Alec G. (1966): El patrón oro: 1880-1914. Inglaterra y Argentina, Buenos Aires, Editorial del Instituto.

Gallo, Ezequiel, y Cortés Conde, Roberto (1967): La formación de la Argentina moderna, Buenos Aires, Paidós.

HAll, A. R. (ed.) (1968): The Export of Capital from Britain 1870-1914, Londres, Methuen \& $\mathrm{Co}$. Ltd.

Jones, Charles (1972): «European Bankers and Argentina, 1880-90», Working Papers $n . * 3$. Business Imperialism Series, Cambridge, Centre of Latin American Studies, 13 pp.

La Nación (1880-87) (diario), Buenos Aires.

La Prensa (1880-87) (diario), Buenos Aires.

La Tribuna Argentina (1881) (diario), Buenos Aires.

L'Economiste Français (1880-87) (semanario financiero), París.

Marichal, Carlos (1984): «Los banqueros europeos y los emprestitos argentinos: rivalidad y colaboración, 1880-1890», Revista de Historia EconómicA, año II, núm. 1, pp. 47.82.

Ministerio de HACIEndA, República Argentina (1880-1887): Memoria anual, Buenos Aires. Ministerio del InTERIOR, República Argentina (1880-1887): Memoria anual, Buenos Aires.

Peters, Harold (1934): The Foreign Debt of the Argentine Republic, Baltimore, The John Hopkins Press.

PlatT, D. C. M. (1983): «Foreign Finance in Argentina from the First Half-Century of Independence», Journal of Latin American Studies, 15, I, pp. 23-47. 
REgaLSKY, Andrés M. (1985): «Las inversiones francesas en ferrocarriles, 1887-1900», VII Jornadas de Historia Económica Argentina, Rosario, 29 pp.

- (inédito): «Los bancos franceses y los créditos de corto plazo al Gobierno argentino, 1880-90», 29 pp.

Registro NAcional (1879-1887) (publicación del Ministerio del Interior), Buenos Aires.

Revue Sudaméricaine (1882-1885) (publicación quincenal), París.

TCh eRnoff, J. (1922): Les syndicats financiers, París.

TERRY, José A. (1893): La crisis, 1885-1892. Sistema Bancario, Buenos Aires.

The Economist (1881-1887) (semanario financiero), Londres.

The Standard (1880) (diario), Buenos Aires.

The South American Journal (1880) (semanario financiero), Londres.

The Statist (1881-1887) (semanario financiero), Londres.

VIDAL, E. (1910): The History and Methods of the Paris Bourse, Washington.

Williams, John H. (1920): Argentine International Trade under Inconvertible Paper Money, Cambridge (Mass.).

WoodrufF, William (1977): *The Emergence of an International Economy», en CIPoLLA, C. (ed.): Economic History of Europe, Londres, Fontana Books (versión en castellano: Editorial Ariel), vol. 4, parte 2. 